\title{
АЛЬТЕРНАТИВА ЗАМЕСТИТЕЛЬНОЙ ТЕРАПИИ КОНЪЮГИРОВАННЫМИ ЭСТРОГЕНАМИ В ХИРУРГИЧЕСКОЙ МЕНОПАУЗЕ У ЖЕНЩИН С ФИБРОЗНО-КИСТОЗНОЙ МАСТОПАТИЕЙ
}

Проблемы заместительной гормональной терапии (ЗГТ) в менопаузе не теряют своей актуальности в настоящее время. Особенно важным представляется вопрос курабельности посткастрационного синдрома (ПКС) у женщин с хирургической менопаузой, поскольку исходные патологические состояния, по поводу которых производилось хирургическое вмешательство, развиваются на фоне относительной или абсолютной гиперэстрогенемии, недостаточности лютеиновой фазы цикла, патологического состояния рецепторов органов-мишеней [1].

Органические изменения органов малого таза развиваются синхронно с патологией молочных желез, в т.ч. с образованием кистозных и фриброзных изменений ткани молочной железы. По определению ВОЗ, фиброзно-кистозная мастопатия (ФКМ) - это «комплекс процессов, характеризующихся широким спектром пролиферативных и регрессивных изменений в тканях молочных желез с формированием ненормальных соотношений эпителиального и соединительнотканного компонентов и образованием в молочной железе изменений фриброзного, кистозного, пролиферативного характера». Именно процессы пролиферации являются объектом пристального внимания клиницистов. С одной стороны, необходимо подобрать комплекс активных веществ с целью снижения патологических эффректов резкого угнетения выработки эстрогенов у женщин с хирургической менопаузой; с другой - эстрогены являются биологическим фактором, способствующим пролиферации тканей стероидзависимых органов, и могут ухудшить ситуацию по отношению к молочным железам.

Данная проблема подбора необходимого препарата либо комплекса препаратов, в т.ч. уменьшающих возможность пролиферативных процессов, стала основой клинического исследования эффрективности сочетания комплексных средств на натуральной растительной основе, действие которых направлено на лечение симптомов менопаузы, в т.ч. и хирургической, и в то же время осуществляющих защиту патологической реакции тканей с учетом эстрогенной рецепции.

Овариоэктомия сопровождается резким снижением уровня наиболее биологически активного эстрогена - 17ß-эстрадиола, уровень которого в первые недели после операции может доходить до следовых значений. В ответ на исчезно- вение продуцируемых яичниками биологически активных стероидов повышается уровень гонадотропинов - лютеинизирующего гормона (ЛГ) в 3-4 раза, фолликулостимулирующего гормона (ФСГ) в 10-15 раз. ПКС, развивающийся после овариоэктомии, характеризуется развитием достаточно тяжелых по клиническому течению и некурабельных симптоматическими препаратами нейровегетативных, психосоматических и обменно-эндокринных нарушений. По данным В.П. Сметник (1997) ПКС характеризуется тяжелым течением у 60\% женщин, перенесших овариоэктомию, у 26\% женщин - умеренными проявлениями и только около 14\% пациенток отмечают климактерические жалобы легкой степени выраженности [2].

Наряду с сосудистой и неврологической симптоматикой в виде приливов жара, парестезий, нестабильности артериального давления, тахикардии десицит эстрогенов является причиной урогенитальных расстройств, которые характеризуются атрофическими изменениями и наблюдаются у 40-60\% пациенток. Развивается сухость слизистой влагалища, зачастую с присоединением местной инфекции и возникновением атрофического вагинита. Пациентки предъявляют жалобы на жжение и зуд. Формируется диспареуния, что приводит к нарушениям сексуальной составляющей, снижению качества жизни, психологическим проблемам. Стрессовое недержание мочи, цисталгии, цистоуретриты также являются последствиями дефицита половых стероидов.

Мышечная и суставная боль, сухость слизистых гортани, глаз также являются неспецифическими симптомами эстрогендефицита.

Развивается вторичный метаболический синдром, характеризующийся повышением уровня липопротеинов низкой плотности, общего холестерина, что приводит в конечном итоге к нарушениям микроциркуляции, метаболическим изменениям в тканях. Происходит также резкое усиление резорбции костной ткани, развитие остеопороза [3]. У пациенток после овариоэктомии максимально выражена несостоятельность механизмов общей антиоксидантной защиты, обусловленная гормональным дистрессом.

Известно, что наиболее раннее назначение ЗГТ в послеоперационном периоде значительно уменьшает проявления постовариоэктомического синдрома. Однако уже доказанным является фракт неблагоприятного влияния

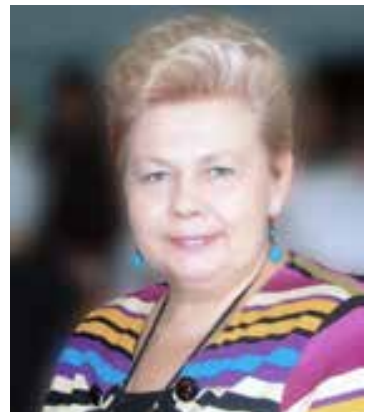

О.В. ГРИЩЕНКО

д.мед.н., просрессор,

заведующая кафедрой акушерства и гинекологии

медицинского фракультета Харьковского национального университета им. В.Н. Каразина, декан педиатрического

фракультета Харьковской

медицинской академии последипломного образования

Н.Г. ГРИЩЕНКО д.мед.н., просрессор кафедры акушерства и гинекологии № 1 Харьковского национального медицинского университета

В.В. БОБРИЦКАЯ

Харьковская медицинская академия последипломного образования

О.Л. ЧЕРНЯК

Харьковская медицинская академия последипломного образования

А.Ю. ЖЕЛЕЗНЯКОВ Харьковская медицинская академия последипломного образования 
конъюгированных эстрогенов на ткань молочной железы при длительном применении ЗГТ, в т.ч. происходит повышение риска злокачественных неоплазий. Этот фракт ставит под сомнение возможность назначения ЗГТ у женщин с ДЗМЖ.

Патогенетической основой заболеваний, по поводу которых проводится оперативное лечение, является нарушение синтеза гонадотропных, стероидных гормонов, пролактина, гормонов щитовидной железы, что соответствует современным представлениям об этиологии и патогенезе развития мастопатии.

Поэтому поиск оптимальных методов ЗГТ в послеоперационном периоде и защиты ткани молочной железы, одновременного лечения мастопатии представляется чрезвычайно актуальным [4].

Поиск терапевтических компонентов тканеселективного действия без гиперпластических эффектов привел к изучению фритопрепаратов, нормализующих уровень центральных и периферических гормонов, рецептивную активность тканей и направленных на снижение эффектов дефицита эстрогенов, В т.ч. и в случаях хирургической менопаузы. Перспективным направлением в данном контексте является использование фитопрепаратов на основе фрито-SERM, которые уже показали свою эффективность по уменьшению вегетососудистых проявлений, обусловленных эстрогенодефицитом. Несмотря на то, что экспериментальные исследования на животных свидетельствуют о возможности фитоэстрогенов стимулировать гиперпластические процессы в эндометрии и молочных железах [11,12], на практике не выявлена достоверная корреляционная связь между приемом фитоэстрогенов и риском канцерогенеза [13]. В естественных условиях фитоэстрогены выступают как селективные модуляторы эстрогеновых рецепторов, они способны оказывать как эстрогенное, так антиэстрогенное действие в зависимости от условий эстрогенной насыщенности организма. Кроме того, фритоэстрогены обладают потенциальной противоопухолевой активностью за счет способности ингибировать активность ряда фрерментов (тирозинкиназы и других протеинкиназ, ароматазы), участвующих в синтезе и метаболизме гормонов. Таким образом, фитопрепараты с эстрогенопозитивной активностью могут быть полезными женщинам с посткастрационным синдромом даже при наличии дисгормональной гиперплазии в молочных железах, но остается открытым вопрос, как помочь таким пациенткам в лечении непосредственно ДГЗМЖ.

Цель нашего исследования заключалась в изучении клинических эффректов сочетания препаратов фитоселективного и эстрогенпротекторного действия заместительной терапии у женщин с хирургической менопаузой и мастопатией.

\section{МАТЕРИАЛЫ И МЕТОДЫ ИССЛЕДОВАНИЯ}

Под наблюдением находились 93 пациентки с хирургической менопаузой в периоде от 1 до 3 мес после операции. У всех женщин обследуемой группы имелись клинические признаки ФКМ, подтвержденной сонографически.

С целью лечения ПКС пациентки получали негормональный фитокомплекс Лайсремин ${ }^{\circledR}$, который производится на основе стандартизованных растительных экстрактов Naturex (Франция) и представляет собой уникальную комбинацию натуральных природных эстроген-прогестагенных гормоноподобных соединений шишек хмеля (патентованный экстракт Lifenol ${ }^{\circledR}$ ), корня пуэрарии лопастной, корневища цимицифуги рацемоза, корней дудника китайского, дикого ямса и биологического кальция. Лайфемин ${ }^{\circledR}$ обладает достаточно мощным эстрогеноподобным потенциалом, который реализуется за счет синергизма действия фитоэстрогенов (8-изопренилнарингенин, 6-изопренилнарингенин, ксантогумол, изоксантогумол, дайдзеин) и фитогормонов (тритерпеновые гликозиды цимицифуги, $\beta$-ситостерин). Кроме того, биологически активные компоненты хмеля и цимицифуги обладают мягким успокаивающим действием, экстракты пуэрарии и дудника китайского («женский женьшень») характеризуются гипохолестеринемическими, гипотензивными, антиаритмическими свойствами, а следовательно, оказывают профилактическое влияние на работу сердечно-сосудистой системы и препятствуют развитию атеросклероза. Экстракт дикого ямса (диоскорея) содержит стероидные прогестагенные составляющие (диосцин, диосгенин), которые защищают эндометрий и молочные железы от гиперпролифератвных процессов, обусловленных влиянием эстрогенов. Природные компоненты жемчужного кальция путем ферментативного гидролиза преобразуются в легко усваиваемый человеческим организмом органический кальций с высокой биодоступностью, необходимый организму женщины для сохранения плотности костной ткани, и предупреждают развитие остеопороза.

Следовательно, Лайфремин ${ }^{\circledR}$ предназначен для купирования симптомов менопаузы, обладает выраженным эстрогеноподобным действием, но лишен гиперпластических эфрфектов, присущих синтетической гормональной терапии. С целью заместительной терапии в послеоперационном периоде пациентки принимали Лайфемин ${ }^{\circledR}$ по капсуле 1 раз в день непрерывно в течение 3-5 мес.

Для лечения ФКМ пациентки получали фитокомплекс Тазалок $^{\circledR}$ с учетом его многовекторного воздействия на звенья патогенеза дисгормональных пролиферативных процессов в молочных железах. Растительный препарат Тазалок ${ }^{\mathrm{TM}}$ можно охарактеризовать как «природный путь от эстрогенной доминанты к доминанте здоровья» у женщин с дисгормональными пролиферативными процессами, поскольку он проявляет антиэстрогенное, прогестеронмоделирующее и антипролиферативное воздействие на железистые и стромальные компоненты репродуктивных органов [5, 6]. Также компоненты данного фитокомплекса характеризуются противовоспалительным, противоотечным, противоопухолевым, седативным и резорбтивным воздействием при кистозных образованиях в яичниках и молочных железах [7]. При ФКМ назначали Тазалок ${ }^{\mathrm{TM}}$ В дозировке по 30 капель 3 раза в день, также в непрерывном режиме в течение 3 мес. Всем пациенткам проводили сонографическое исследование молочных желез до оперативного лечения, через 30-45 дней после операции, а также спустя 3 мес.

Группой сравнения послужили 25 пациенток с хирургической менопаузой и ФКМ, не получавших препаратов заместительной терапии эстрогенами, которым были назначены различные комплексы синдромологической терапии: кардиотропные, гипотензивные, седативные препараты, комплексы витаминов и микроэлементов. Среди пациенток основной группы 28 (41\%) женщин были в возрастном периоде 39-45 лет и 40 (59\%) 46-57 лет. Контрольную группу составили соответственно $9(36 \%)$ и $16(64 \%)$ женщин. 
Оперативные вмешательства проводились по поводу сочетания множественной миомы матки и кистомы яичника у 62 (67\%) пациенток обеих групп наблюдения, эндометриоидных цистаденом 13 (13,9\%), в т.ч. двусторонних у 5 (5,3\%), текомы яичника у 3 (3,2\%), пограничных кист яичников у $3(3,2 \%)$, серозной цистаденомы в сочетании с кистозной дегенерацией второго яичника у $6(6,4 \%)$ женщин.

За 7-10 дней до оперативного вмешательства наряду с традиционным объемом обследования проводилось гормональное исследование: определяли уровни пролактина, ФСГ, ЛГ, тиреотропного гормона, фрракции тиреоидных гормонов. Также определяли уровень холестерина и фракций липопротеинов. Следует отметить, что исходно имели место явления гипотиреоза у 42 (56\%) женщин, диагноз аутоиммунного тиреоидита был поставлен 47 (62\%) пациенткам. Уровень пролактина, близкий к верхней границе нормы, имели 36 (48\%) пациенток. Концентрации ФСГ и ЛГ в предоперационный период также были близкими к верхней границе нормы в большинстве наблюдений. Уровень холестерина и липопротеинов не имел существенных отличий от таковых в условных возрастных нормах. Проводилось также исследование онкомаркеров СА-125, СА-15.3: клинически значимого повышения их уровней у пациенток исследуемых групп выявлено не было.

В послеоперационном периоде через 3 мес после проведенного лечения оценивались как клинические проявления хирургической менопаузы, так и дополнительные исследования биохимического спектра, гормональные исследования. Сонографически оценивались морфологические особенности молочных желез, степень визуализации признаков ФКМ: величина кист, интенсивность фиброзных компонентов, состояние млечных протоков.

Клинические проявления хирургической менопаузы до лечения у женщин основной и контрольной групп существенно не отличались и составили: вазомоторные симптомы (приливы, ночная потливость, головная боль) наблюдались соответственно у 60 (88\%) и 22 (88\%) пациенток; эмоциональнопсихические (раздражительность, сонливость, повышенная утомляемость, беспокойство, тревога, депрессия) - у 32 (47\%) и 13 (52\%); урогенитальные (сухость во влагалище, боль при половом акте, зуд и жжение) - у 14 (20,5\%) и 5 (21,5\%); кардиологические (кардиалгия, гипертензия, нестабильность артериального давления) - у 27 (39,7\%) и 9 (36,0\%) соответственно. Степень выраженности климактерических симптомов оценивали по шкале модифицированного менопаузального индекса (ММИ). Морфологические признаки ФКМ также были аналогичными по структурным составляющим у пациенток обеих групп: определялись участки повышенной эхоплотности, полигональной формы, с эхонегативными включениями в виде мелких кист, кистозное расширение млечных протоков, единичные кисты до 5-7 мм.

\section{РЕЗУЛЬТАТЫ ИССЛЕДОВАНИЯ И ИХ ОБСУЖДЕНИЕ}

В результате применения препарата Лайфемин ${ }^{\circledR}$ В сочетании с препаратом Тазалок ${ }^{\text {TM }}$ гормональные исследования показали относительно низкие уровни ЛГ и ФСГ у женщин основной группы (выше условной нормы в 3,5 раза); в контрольной группе их уровень превышал норму в 9,2 раза. Липидный спектр в контрольной группе незначительно превышал показатели основной группы. Уровень тиреотропных гормонов принципиально не изме- нился. Повысились показатели свертывающей системы крови у женщин группы сравнения, принимавших синдромологическую терапию. Минеральная плотность костей (по данным денситометрии) у пациенток основной группы превышала контрольную в 1,2 раза.

После 3-месячного курса терапии были получены следующие результаты: вазомоторные жалобы остались у 13 (19,1\%) пациенток основной группы и у 17 (68\%) пациенток группы сравнения; эмоционально-психические - у 8 (11,8\%) и 6 (24\%) соответственно (рис. 1). Во время терапии наблюдалось значительное снижение степени выраженности менопаузальных симптомов по шкале ММИ, особенно по показателю «приливы» (рис. 2). Особого внимания заслуживает положительное действие фритокомплекса Лайфемин ${ }^{\circledR}$ на степень выраженности урогенитальных расстройств: в основной группе после курса терапии они выявлялись у 6 (8,8\%) женщин, в группе сравнения - у 5 (21,5\%) (рис. 1). Возможно, имело место усиление клинических эффектов на фоне дополнения терапии препаратом Тазалок ${ }^{\mathrm{TM}}$, так как составляющие компоненты последнего обладают также мочегонным, противоотечным и резорбтивным действием.

Кроме того, следует отметить нормализацию метаболических показателей, а именно стабилизацию артериального давления: в основной группе после лечения кардиоваскулярные жалобы зафиксированы всего у 4 (13,2\%) пациенток, в контрольной - у 5 (20,0\%) (рис. 1), а также стабилизацию веса пациенток основной группы по сравнению с контрольной после оварио- и гистерэктомии, что свидетельствует о профилактике развития метаболического синдрома у женщин, принимавших Лайфемин ${ }^{\circledR}$.

В результате терапии у женщин, которым назначали Тазалок ${ }^{\mathrm{TM}}$, получены визуальные результаты положительной динамики органических изменений молочных желез (рис. 3, 4) - частичная редукция кист у 29 (42,6\%) пациенток, уменьшение эхоплотности фриброзных элементов у 44 (64,7\%), уменьшение диаметра у 53 (77,9\%), отсутствие визуализации млечных протоков у 5 (7,3\%) женщин. Полученные нами положительные результаты эффрективности препарата Тазалок ${ }^{\mathrm{TM}}$ при дисгормональных заболеваниях молочных желез коррелируют с результатами других клинических исследований по его применению в лечении данной патологии [5, 7,9,10].

Таким образом, можно констатировать хороший клинический эффект фитокомплекса Лайфемин ${ }^{\circledR}$ как средства патогенетической терапии в случаях хирургической менопаузы для профилактики ранних и отдаленных осложнений ПКС. Участие тканеселективных фритомолекул Лайфемин ${ }^{\circledR}$ оказывает положительное влияние на метаболизм тканей, циркуляторную и нейроэндокринную составляющие менопаузальных расстройств. Одновременное назначение препарата Тазалок ${ }^{\mathrm{TM}}$ способствует нормализации состояния молочных желез, демонстрирует положительный клинический эффект терапии ФКМ, по-видимому, за счет уменьшения локального стероидогенеза и угнетения синтеза простагландинов типа $\mathrm{E}_{2}$. Суммация биологических эффректов растительных комплексов Лайфремин ${ }^{\circledast}$ и Тазалок ${ }^{\mathrm{TM}}$ позволяет стабилизировать эмоциональное состояние пациентки, что очень важно после проведенного оперативного вмешательства. Несмотря на то, что Лайфемин ${ }^{\circledR}$ содержит защитный прогестагенный компонент диоскорею, включение в схему лечения растительного препарата Тазалок ${ }^{\mathrm{TM}}$ является идеальным вариантом терапии прикрытия при использовании как фитоэстрогенов, так и ЗГТ. 


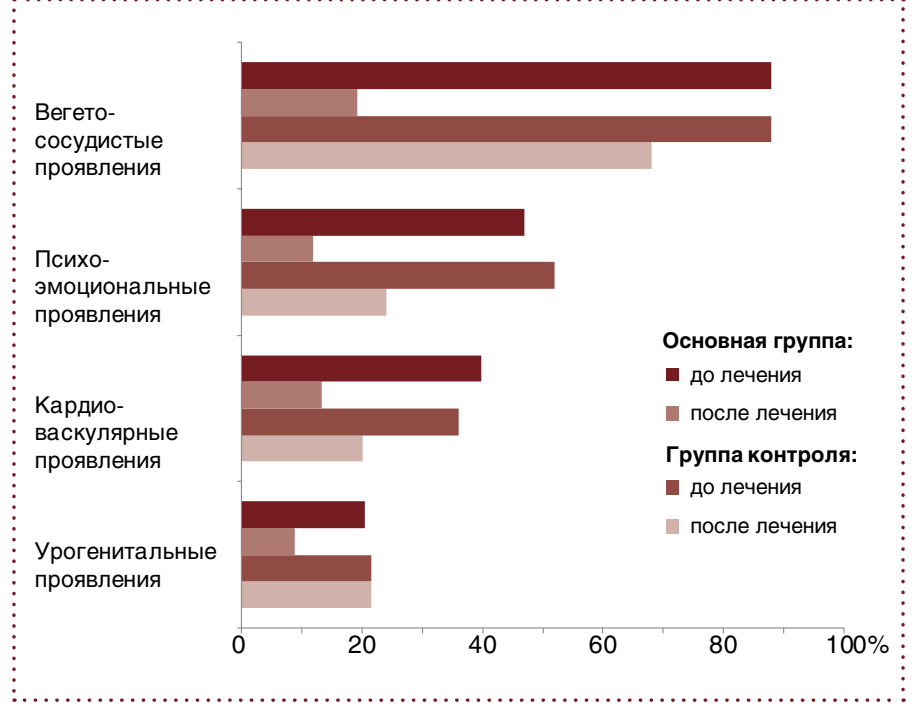

РИС. 1.

ЭФФЕКТИВНОСТЬ ЛЕЧЕНИЯ МЕНОПАУЗАЛЬНЫХ СИМПТОМОВ У ЖЕНЩИН С ХИРУРГИЧЕСКОЙ МЕНОПАУЗОЙ

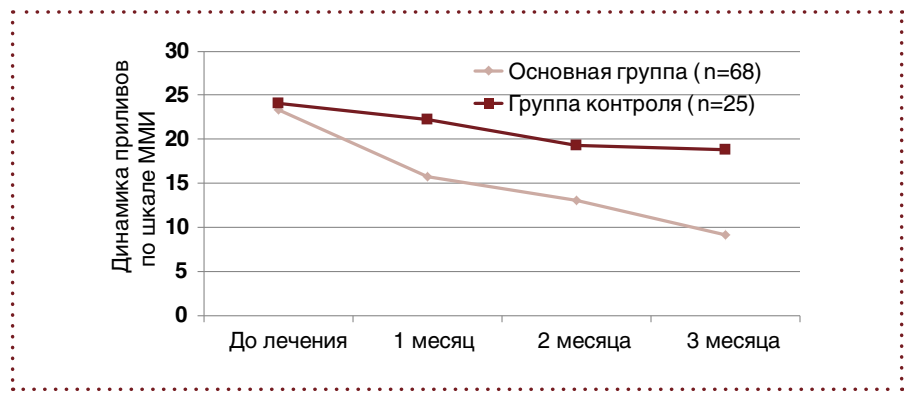

PИC. 2 .

ДИНАМИКА ИЗМЕНЕНИЯ СТЕПЕНИ ВЫРАЖЕННОСТИ ВЕГЕТОСОСУДИСТЫХ СИМПТОМОВ У ПАЦИЕНТОК С ПКС НА ФОНЕ ЛЕЧЕНИЯ

\section{ВЫВОДЫ}

1. Комплекс эстроген-прогестагенных фритомолекул с биоактивным кальцием Лайфемин ${ }^{\circledR}$ является эффрективным средством в лечении комплекса менопаузальных расстройств, в т.ч. и в результате хирургической менопаузы.

2. Тазалок ${ }^{\mathrm{TM}}$ является эфффективным препаратом лечения ФКМ как средство, снижающее эстрогензависимые эффекты и улучшающее морфологию молочной железы.

3. Клинически обоснованным следует считать одновременное назначение эстроген-прогестагенных фитомолекул фитопрепаратов Лайсремин ${ }^{\circledast}$ с целью заместительной фритотерапии и Тазалок ${ }^{\mathrm{TM}}$ для лечения сопутствующей патологии молочных желез.

4. Ультразвуковой мониторинг является обязательным методом контроля эффективности лечения ФКМ на фоне лечения хирургической менопаузы, а также контроля отсутствия отрицательных последствий фитоселективной эстрогеноподобной терапии.

\section{ПЕРСПЕКТИВЫ ИССЛЕДОВАНИЯ}

Перспективным является исследование эфрфектов при длительном применении заместительной терапии Лайфемином ${ }^{\circledR}$ - до нескольких лет непрерывного приема. В комплекс терапии может быть включен препарат гепатопротекторного действия, а также препараты, улучшающие кислородный метаболизм тканей с учетом усиления метаболического действия.

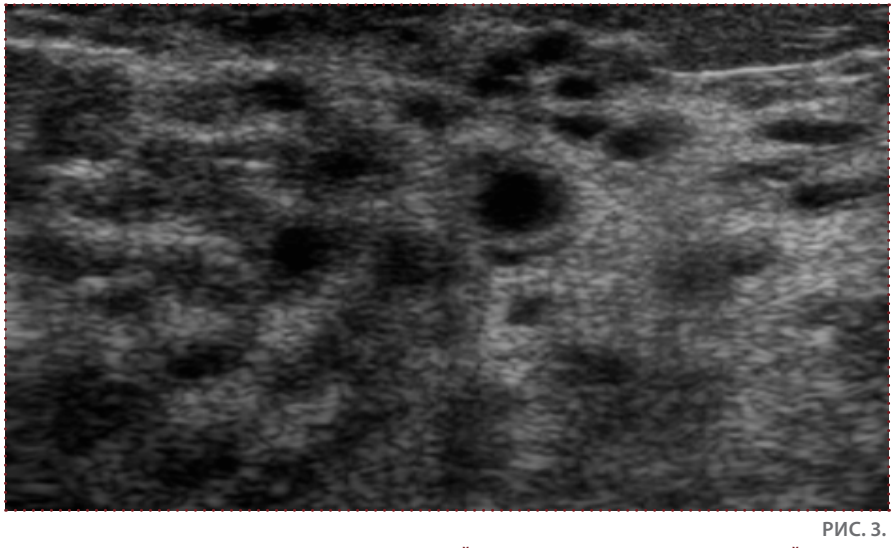

СОНОГРАФИЧЕСКАЯ КАРТИНА МОЛОЧНОЙ ЖЕЛЕЗЫ ПАЦИЕНТКИ ОСНОВНОЙ ГРУППЫ (5 СУТ ПОСЛЕ ОПЕРАТИВНОГО ЛЕЧЕНИЯ): ПРИЗНАКИ ФКМ - УЧАСТКИ КИСТОЗНОГО РАСШИРЕНИЯ МЛЕЧНЫХ ПРОТОКОВ, УЧАСТКИ ФИБРОЗА

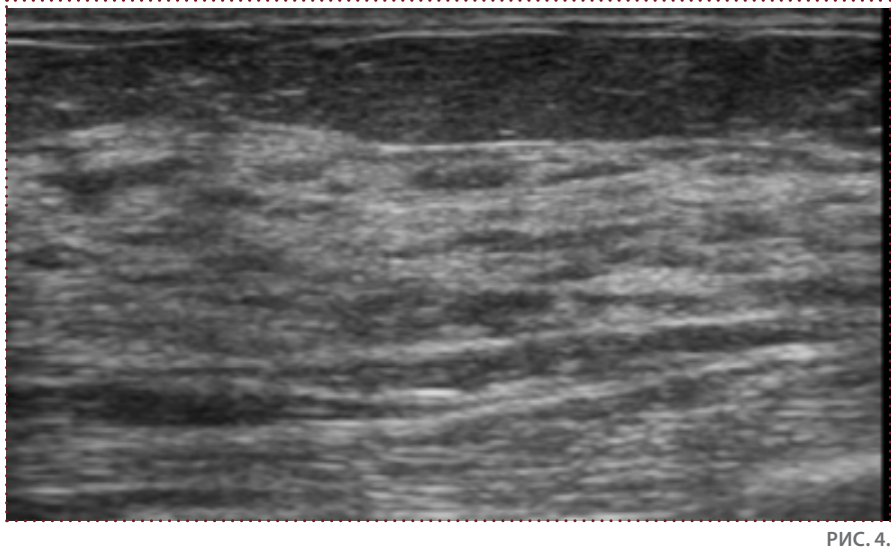

УЗИ ПАЦИЕНТКИ ОСНОВНОЙ ГРУППЫ: УМЕНЬШЕНИЕ КИСТОЗНЫХ ЭЛЕМЕНТОВ, СТЕПЕНИ РАСШИРЕНИЯ МЛЕЧНЫХ ПРОТОКОВ - РЕЗУЛЬТАТ СОЧЕТАННОЙ ТЕРАПИИ ЛАЙФЕМИНОМ И ТАЗАЛОКОМ ${ }^{\top M}$ (З МЕС ПОСЛЕ ОПЕРАТИВНОГО ЛЕЧЕНИЯ)

\section{ЛИТЕРАТУРА}

1. Вихляева Е.М. Постменопаузальная терапия. - М.: Медпресс-информ, 2008. - С. 48-50.

2. Дубоссарская 3.М., Дубоссарская Ю.А. Метаболический синдром и гинекологические заболевания // Медицинские аспекты здоровья женщины. 2010. - № 2(29). - С. 27-38.

3. Поворознюк В.В. Остеопороз: фрактори ризику, класифікація, лікування // Нова медицина. - 2002. - № 5. - С. 38-41.

4. Роженко А.В. Новий підхід до корекції системних порушень у жінок 3 хірургічною менопаузою // Педіатрія, акушерство та гінекологія. - 2010. - № 4.

5. Татарчук Т.Ф., Калугина Л.В., Ефименко О.А. Опыт лечения масталгии у пациенток с дисгормональными заболеваниями молочных желез //Репродуктивная эндокринология. - № 3 (5). - 2012. - С. 53-57.

6. Резніков О.Г. Антиестрогенна активність фрітопрепарату Тазалок ${ }^{\text {тм: }}$ результати експериментального дослідження / О.Г. Резніков, Л.В. Тарасенко, П.В. Сініцин та ін. // Репродуктивная ендокринология. - 2012. - № 1 (3) . - С. 90-92

8. Корнацька А.Г., Дубенко О.Д. Фітоселективна терапія у жінок 3 безплідністю та доброякісними захворюваннями молочних залоз на етапах реабілітації репродуктивної функції //Здоровье женщины. - №6 (72) . - 2012. C. $218-221$.

9. Товстановская В.А., Воробей-Виховская В.Н., Сахарова И.А. Новое слово в негормональной терапии фиброзно-кистозной мастопатии. // Здоровье женщины. - №1 (47)/2010.С.64-66

10. Грищенко О.В., Абдуллаев Р.Я., Доленко О.В., Пак С.А. Ультразвуковая диагностика и комплексное лечение дифффузной фибрознокистозной мастопатии у женщин репродуктивного возраста.

//Здоровье женщины. - №9. (45)/2009. - 134-136.

11. Wang T.T., Sathyamoorthy N., Phang J.M. Molecular effects of genistein on estrogen receptor mediated pathways. Carcinogenesis. 1996 Feb;17(2):271-5.

12. Rimoldi G., Christoffel J., Wuttke W. Morphologic changes induced by oral long-term treatment with 8-prenylnaringenin in the uterus, vagina, and mammary gland of castrated rats. Menopause. 2006 Jul-Aug;13(4):669-77

13. Miller P.E., Snyder D.C. Phytochemicals and Cancer Risk: A Review of the Epidemiological Evidence. Nutr Clin Pract. 2012 Oct;27(5):599-612. 